\title{
Deviated nasal septum hinders intranasal sprays: a computer simulation study*
}

Dennis O. Frank1, Julia S. Kimbell', Daniel Cannon², Sachin S. Pawar², and John S. Rhee ${ }^{2}$
Rhinology 50: 311-318, 2012

DOI: 10.4193/Rhino12.053

*Received for publication:

April 1, 2012

Accepted: May 26, 2012

\section{Summary}

Background: This study investigates how deviated nasal septum affects the quantity and distribution of spray particles, and examines the effects of inspiratory airflow and head position on particle transport.

Methods: Deposition of spray particles was analysed using a three-dimensional computational fluid dynamics model created from a computed tomography scan of a human nose with leftward septal deviation and a right inferior turbinate hypertrophy. Five simulations were conducted using Fluent ${ }^{\mathrm{T} m}$ software, with particle sizes ranging from 20-110 $\mu \mathrm{m}$, a spray speed of $3 \mathrm{~m} / \mathrm{s}$, plume angle of $68^{\circ}$, and with steady state inspiratory airflow either present $(15.7 \mathrm{~L} / \mathrm{min})$ or absent at varying head positions.

Results: With inspiratory airflow present, posterior deposition on the obstructed side was approximately four times less than the contralateral side, regardless of head position, and was statistically significant. When airflow was absent, predicted deposition beyond the nasal valve on the left and right sides were between $16 \%$ and $69 \%$ lower and positively influenced by a dependent head position.

Conclusion: Simulations predicted that septal deviation significantly diminished drug delivery on the obstructed side. Furthermore, increased particle penetration was associated with presence of nasal aiflow. Head position is an important factor in particle deposition patterns when inspiratory airflow is absent.

Key words: computational fluid dynamics, septal deviation, intranasal spray, particle deposition, inspiratory airflow

\section{Introduction}

Intranasal medications such as topical intranasal steroids (INS) or intranasal antihistamines are widely used to treat a variety of sinonasal inflammatory, allergic, and infectious disorders. In addition, intranasal drug delivery can be used for systemically acting drugs that are difficult to deliver through routes other than injection, such as insulin and vaccines ${ }^{(1)}$. However, despite the popularity of aqueous nasal sprays, experimental studies have shown that many spray devices deposit a significant amount of their drug in the anterior, less metabolically active regions of the nose ${ }^{(2-6)}$.
A combination of drug, device, and patient factors can contribute to the efficacy of intranasal drugs. These include drug formulation characteristics, delivery device design, delivery technique, site of deposition, nasal anatomy, and underlying sinonasal medical conditions ${ }^{(7,8)}$. Nasal anatomy is particularly significant since it is characterized by variations across individuals. The efficacy of drug delivery using nasal sprays has not been well described in patients with nasal airway obstruction (NAO) due to anatomic nasal deformities such as nasal septal deviation. Most studies characterizing intranasal drug deposition pat- 
terns have used subjects with normal sinonasal anatomy ${ }^{(6,9-12)}$. Additionally, individual anatomic differences and head position have been shown to affect intranasal drug deposition ${ }^{(7)}$. In our previous work ${ }^{(3)}$, we compared drug delivery penetration past the nasal valve of aqueous spray pumps and nebulizers in a patient with deviated nasal septum. However, the presence or absence of inspiratory airflow and head position on topical nasal medications were not considered in this study.

Anatomic nasal deformities in combination with inspiratory airflow and head position have the potential to significantly alter intranasal drug delivery and limit the efficacy of these medications. Computational fluid dynamics (CFD) methods have been shown to render numerical predictions of airflow patterns and particle trajectories in complex geometries such as the human respiratory system ${ }^{(2,3,13-32)}$.

The objective of the present study was to investigate the impact of nasal septal deviation on spray particle penetration and deposition using CFD techniques and to examine the influence of inspiratory airflow and head positioning. More specifically, the simulated data generated were used to test the following null hypotheses:

Hypothesis \#1: Spray particle penetrations past the nasal valve for both (obstructed left and "normal" right) sides of the nasal cavity are equal.

Hypothesis \#2: The presence or absence of inspiratory airflow does not improve efficacy of particle transport within the nasal cavity.

Hypothesis \#3: Head position does not impact spray particle deposition beyond the anterior region of the nose.

\section{Materials and methods}

Nasal Model Construction

A three-dimensional (3D) nasal airway model of a 30 -year-old Caucasian female subject (weight, 86.4 kg; height, $164.6 \mathrm{~cm}$ ) with a moderate to severe broad leftward deviation of the mid-portion of the septum and a compensatory right inferior turbinate hypertrophy (Figure 1) was created from a CT scan containing 142 slices, with an increment of $0.625 \mathrm{~mm}$, and a pixel size of $0.313 \mathrm{~mm}$. The subject provided written informed consent as required and approved by the Institutional Review Board at Medical College of Wisconsin. The CT scan files were imported into the medical imaging software Mimics ${ }^{\mathrm{TM}} 13.1$ (Materialise, Inc., Plymouth, MI, USA), and a 3D reconstruction of the main nasal airways was constructed from which the paranasal sinuses were omitted. The 3D reconstruction was exported from Mimics ${ }^{\mathrm{TM}}$ in STL (stereolithography) file format into the CAD and mesh generating software package ICEM-CFD ${ }^{\mathrm{TM}} 12.1$

(ANSYS, Canonsburg, PA, USA). Planar nostril and outlet surfaces as well as regions for tracking particle deposition were constructed as shown in our previous study ${ }^{(3)}$. The nasal cavity was separated into the following regions:

- left and right anterior lateral wall

- left and right anterior septum

- left and right middle lateral wall

- left and right middle septum

- nasopharynx

The anterior regions ranged from the nostrils up to the nasal valve area; the middle regions covered the turbinates and adjacent nasal septum, and the nasopharynx was defined as posterior to the turbinates and septum.

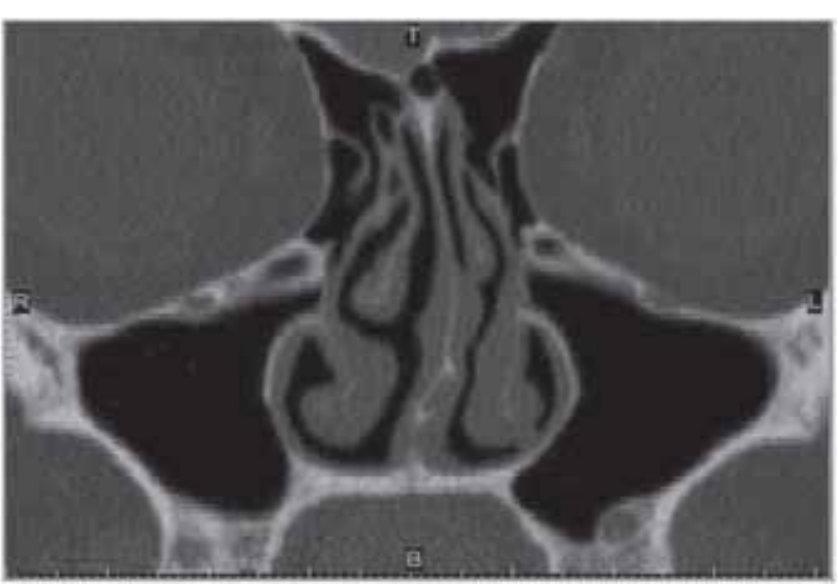

Figure 1. Coronal view showing leftward septal deviation. This diagram is reproduced with permission from Frank et al. ${ }^{(3)}$

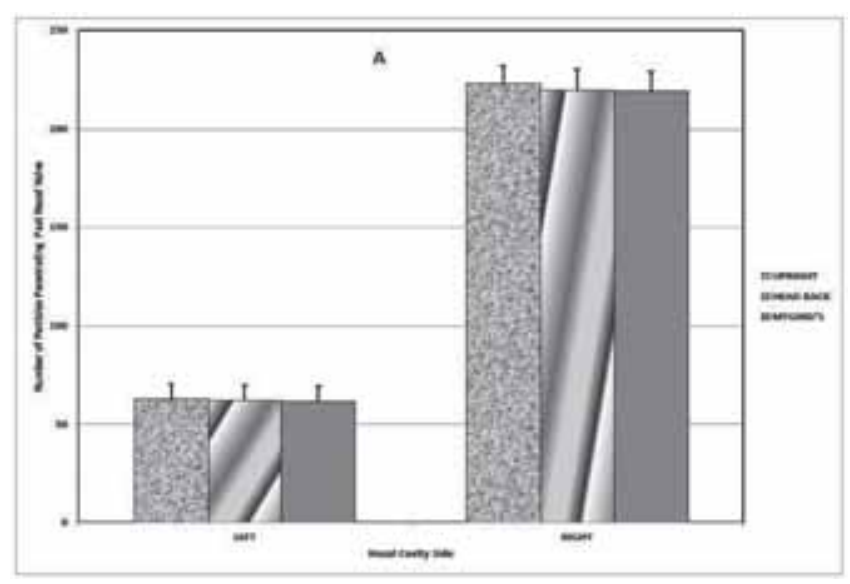

Figure 2. Aerosol particle deposition posterior of the nasal valve area on the right and left (obstructed) sides of the airway.

The bars indicate the means + standard deviation. (A) Airflow Present. (B) Airflow Absent. 


\section{Head Positions}

Spray particle simulations were carried out using three different head positions (described below) that have been experimentally studied as well as recommended by most manufactures of topical INS sprays $(7,11,33)$.

(1) Head is held upright in a neutral position at about $0^{\circ}$ to the vertical plane identical; "head upright position." Head is tilted back at about $45^{\circ}$ to the vertical plane; "head back position." Head is extended just off the edge of a bed or table at about $90^{\circ}$ to the vertical plane while lying down in a supine position; "Mygind's position."This position as pointed out by Merkus et al..$^{(7)}$ was first described by Proetz in 1926 and then modified by Mygind in 1979.

Numerical simulation of airflow and particle trajectories In order to solve the equations that govern fluid flow, a computational mesh of the airspaces was created in ICEM-CFD ${ }^{\mathrm{TM}}$ using approximately 4 million graded tetrahedral elements with a three-layer prism-element boundary. This is consistent with an in house mesh density study that showed that about 4 million elements will provide mesh independent numerical results.

For the case when airflow was present, steady-state, laminar inspiratory airflow was simulated using the CFD software package Fluent ${ }^{\text {TM }}$ 12.1.4 (ANSYS, Inc., Canonsburg, PA, USA) under pressure-driven conditions. Laminar flow is sufficient in this study since we are simulating resting breathing rate. By simulating at steady-state, this implies that time-dependent variables were held constant and all derivatives with respect to time were zero. The boundary conditions specified in Fluent ${ }^{\mathrm{TM}}$ to determine the airflow field were identical to those previously used: ${ }^{(3,14,34)}$

- $\quad$ A "wall" condition assuming that the walls were stationary with zero air velocity at the air-wall interface.

- A "pressure-inlet" condition at the nostrils with gauge pressure set to zero.

- $\quad$ A "pressure-outlet" condition at the outlet with gauge pressure set to -25.4 Pa that generated a target steadystate flow rate of $15.7 \mathrm{~L} / \mathrm{min}$. This flow rate was twice the minute volume (amount of air inhaled in $1 \mathrm{~min}$, defined as tidal volume times respiratory rate) as estimated from body weight using gender-specific power law curves derived by Garcia and colleagues ${ }^{(19)}$.

These authors concluded that data from the 1994 report of the International Committee on Radiation Protection (ICRP) was the best source for variation in minute volume by age and gender. Using the ICRP data, Garcia and colleagues ${ }^{(18,19)}$ derived the following equations:

Males (sitting awake): VE $=(1.36 \pm 0.10) \mathrm{M} 0.44 \pm 0.02$

Females (sitting awake): $\mathrm{VE}=(1.89 \pm 0.40) \mathrm{M} 0.32 \pm 0.06$ where $\mathrm{VE}=$ minute volume in liters per minute $(\mathrm{L} / \mathrm{min}), \mathrm{M}=$ body mass in kilograms (kg). These airflow rates are descriptive of ventilation during sedentary activities such as watching TV or driving a car $^{(35)}$. Airflow rates for steady-state inspiration were calculated by assuming that the duration times of inspiration and expiration were the same, so that the airflow rate for inspiration alone was twice the minute volume. For the case when airflow was absent, a similar simulation to the airflow-present case above was conducted in Fluent ${ }^{\mathrm{TM}}$ except that gauge pressure was set to $0 \mathrm{~Pa}$ at the outlet.

The spray release was defined to be $0.5 \mathrm{~cm}$ into the nasal vestibule from the nostril surface on each side. This $0.5 \mathrm{~cm}$ distance was the largest of those used previously by Kimbell and colleagues ${ }^{(2)}$ that fit into the nasal vestibule of this patient. Spray was directed laterally or to the side, away from the septum and toward the outer portion of the eye as recommended by Benninger et al. ${ }^{(33)}$. The angle of spray insertion was maintained for each side of the nose without regard to head position. The particle sizes $(20-110 \mu \mathrm{m})$, and spray plume angle of 680 considered in this study resemble the Pfeiffer spray pump PF-80 used by Cheng and colleagues ${ }^{(10)}$. A spray velocity of $3 \mathrm{~m} / \mathrm{s}$ was chosen as within the average velocity range of most commercially available sprays $(1-14.7 \mathrm{~m} / \mathrm{s})^{(2,36)}$. In addition, the discharge velocity of flunisolide (though unknown) was estimated to be $370 \mathrm{~cm} / \mathrm{s}(3.7 \mathrm{~m} / \mathrm{s})^{(37)}$. The different head positions were simulated by setting appropriate $x, y$, and $z$ components to conform to the direction of gravitational acceleration.

Particle trajectories were calculated using the Discrete Phase Model in Fluent ${ }^{\mathrm{TM}}$, assuming unit density and spherical particles, using Lagrangian equations of motion for particulate motion, until particle deposited or exited the nasal airway. Particles that exited the nasal airways at the outlet via the nasopharynx were categorized as "Escaped." For particles that deposited in the nasal cavity, the region in which each particle deposited was tracked. The "solid cone" injection type was specified in Fluent ${ }^{\mathrm{TM}}$ for the particle streams that emanated from the spray release position, which releases streams at randomly dispersed angles throughout the spray cone region. To adequately characterize the PF-80 pump in Fluent ${ }^{\mathrm{TM}}$, we used Rosin Rammler Particle Size Distribution (RRPSD) set to range in aerodynamic diameter from 20 to $110 \mu \mathrm{m}$ with mean diameter of $66.7 \mu \mathrm{m}$ and spread distribution parameter of 2.95. A total of 1000 particle streams were released from each nostril. Analysis and visualization of results were conducted using Fluent ${ }^{\mathrm{TM}}$ and the post-processing software package Fieldview ${ }^{\text {TM }} 12$ (Intelligent Light, Lyndhurst, PA, USA).

\section{Statistical analysis}

Spray particle simulations were conducted five times. The number of simulations was obtained by determining the sample size 
Table 1. Mean numbers of particles deposited into various regions of the nasal cavity on left (septal deviation) and right sides. Five spray particle simulations were conducted, with 1000 particle streams released in each simulation.

\begin{tabular}{|c|c|c|c|c|c|c|c|c|c|c|c|c|c|}
\hline \multirow[t]{2}{*}{$\frac{3}{0}$} & \multirow[t]{2}{*}{$\begin{array}{l}\frac{5}{0} \\
\frac{7}{5} \\
\frac{8}{0} \\
\frac{0}{80} \\
\frac{d}{0}\end{array}$} & \multicolumn{2}{|c|}{ 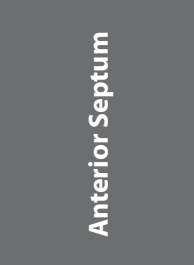 } & \multicolumn{2}{|c|}{ 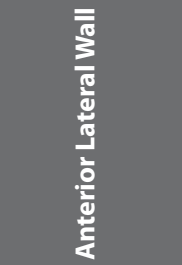 } & \multicolumn{2}{|c|}{ 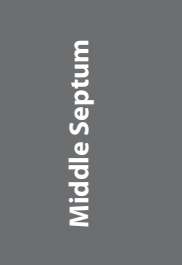 } & \multicolumn{2}{|c|}{  } & \multicolumn{2}{|c|}{ 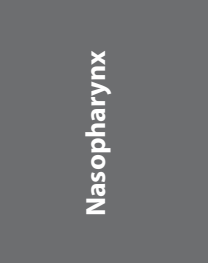 } & \multicolumn{2}{|c|}{ 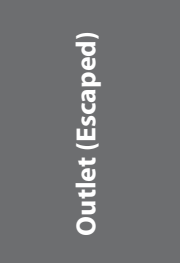 } \\
\hline & & Left & Right & Left & Right & Left & Right & Left & Right & Left & Right & Left & Right \\
\hline \multirow{4}{*}{ Present } & Upright & 329.8 & 132.2 & 607.6 & 644.8 & 56.0 & 121.4 & 6.6 & 101.6 & 0.0 & 0.0 & 0.0 & 0.0 \\
\hline & Head Back & 332.0 & 136.8 & 605.8 & 643.2 & 55.2 & 116.6 & 7.0 & 103.4 & 0.0 & 0.0 & 0.0 & 0.0 \\
\hline & Mygind's & 330.8 & 135.8 & 607.6 & 645.0 & 55.4 & 114.6 & 6.2 & 104.6 & 0.0 & 0.0 & 0.0 & 0.0 \\
\hline & Upright & 367.4 & 224.6 & 617.4 & 703.4 & 9.2 & 47.4 & 6.0 & 24.6 & 0.0 & 0.0 & 0.0 & 0.0 \\
\hline \multirow[t]{2}{*}{ Absent } & Head Back & 243.4 & 102.0 & 727.6 & 788.4 & 23.6 & 67.6 & 5.4 & 42.0 & 0.0 & 0.0 & 0.0 & 0.0 \\
\hline & Mygind's & 240.6 & 89.8 & 653.8 & 779.8 & 33.8 & 40.0 & 71.8 & 90.4 & 0.0 & 0.0 & 0.0 & 0.0 \\
\hline
\end{tabular}

Table 2. Testing the null hypothesis that spray particle penetrations past nasal valve for both sides of the nasal cavity are equal (Hypothesis \#1). The values were presented as means \pm standard deviation and were compared with the Student's t-test. P $<0.05$ indicate statistical significance (all cases).

\begin{tabular}{|c|c|c|c|c|}
\hline Head Position & Airflow & Left Side $(n=5)$ & Right side $(n=5)$ & p-value \\
\hline \multirow[t]{2}{*}{ Upright } & Present & $62.6 \pm 7.96$ & $223.0 \pm 8.97$ & $<0.00001$ \\
\hline & Absent & $15.2 \pm 2.05$ & $72.0 \pm 6.44$ & 0.00001 \\
\hline \multirow{2}{*}{ Head Back } & Present & $62.2 \pm 7.79$ & $220.0 \pm 10.51$ & $<0.00001$ \\
\hline & Absent & $29.0 \pm 1.22$ & $109.6 \pm 10.01$ & 0.00005 \\
\hline \multirow[t]{2}{*}{ Mygind's } & Present & $61.6 \pm 7.77$ & $219.2 \pm 10.03$ & $<0.00001$ \\
\hline & Absent & $105.6 \pm 9.5$ & $130.4 \pm 9.99$ & 0.00385 \\
\hline
\end{tabular}

required to estimate the true population mean of the number of particles depositing on the various regions of the nasal cavity at a $95 \%$ confidence level so that the sample means of the number of deposited particles would lie within six particles of the actual population mean, where six is the maximum error (or half width) of a $95 \%$ confidence interval for hypothesis \#1. Statistical power analysis was conducted to obtain the observed power when $\mathrm{n}=5$ for hypothesis \#1. For "head upright" and "head back" positions, we obtained a power of 1 , and a power of 0.55 for the Mygind's position.

The mean number of particles depositing on the various regions of the nose when spray was released into the left (obstructed) or right side of the nasal cavity, in one of three head positions, and when inspiratory airflow was either present at $15.7 \mathrm{~L} / \mathrm{min}$ or absent was calculated and tabulated. The simulated data generated were used to test the aforementioned null hypotheses. The Student's t-test was used to test hypotheses \#1 and \#2 since two independent samples were compared (left and right sides for hypothesis \#1; airflow present and absent for hypothesis \#2), while analysis of variance (ANOVA) was used to test hypothesis \#3 because three independent samples representing head positions were compared. Statistical analyses were carried out using Microsoft Excel ${ }^{\mathrm{TM}} 2007$ (Microsoft Corp., Redmond, WA, USA) and MATLAB $^{\text {TM }}$ version R2010b (Mathworks, Inc., Natick, MA, USA); a p-value less than 0.05 implied statistical significance.

\section{Results}

Simulations predicted that most of the spray particles deposited in the anterior region of the nose, regardless of nasal side, head position, or airflow presence (Table 1). In addition, simulated results in Table 1 show the anterior lateral wall had substantially more deposition than anterior septal wall regardless of nasal side, head position, or airflow presence, with a somewhat greater effect on the right side. Whereas, the middle region revealed greater deposition on the septum than on the lateral wall regar- 
dless of nasal side or presence of airflow for the "head upright" and "head back" positions. The Mygind's position had higher middle lateral wall deposition in the case when airflow was absent. For both breathing states, no particles were predicted to deposit in the nasopharynx, and no particles exited the airway. CFD results in Figure $2 \mathrm{~A}$ show that about four times as many particles deposited past the nasal valve on the right side than on the obstructed (left) side when airflow was present. Higher posterior deposition was also evident when inspiratory flow was absent (Figure 2B) except for the Mygind's head position.

Results of test of hypothesis \#1 (Table 2) demonstrate that there is significant difference in spray particle deposition past the nasal valve between the obstructed (left) and right sides for every head position, and whether inspiratory airflow was presence or not. In the "head upright" position with airflow present, the impact of septal deviation on particle transport was depicted in Figure 3; aerosolized particle deposition pattern beyond the anterior lateral wall was evidently lower on the obstructed side compared to the right side. The presence or absence of airflow was statistically significant in determining the efficiency of particle transport within the nasal cavity, regardless of head position and side of nasal passage (Hypothesis \#2; Table 3). In general, inspiratory airflow improved particle transport (Figure 2), with the exception of the Mygind's position where deposition on the obstructed side was predicted to improve when airflow was absent. Table 4 provides a summary of test of hypothesis \#3. With airflow present, simulation predicted that the effect of head position on spray particle deposition beyond the anterior region of the nose was not statistically significant for either side of the nasal passage. However, in the case where airflow was absent, head position significantly influenced deposition patterns posterior of the nasal valve.

\section{Discussion}

Prior research on topical drug deposition has been performed in patients with normal nasal anatomy; therefore, drug deposition in patients with anatomic abnormalities including septal deviation has not been well described. Furthermore evidence is lacking on how best to instruct patients in the use of their nasal sprays to optimize spray penetration and distribution in the presence of a common anatomic deformity such as a septal deviation, let alone those with normal sinonasal anatomy. In 2004, the American Academy of Otolaryngology-Head and Neck Surgery Foundation (AAO-HNSF) conducted a systematic review of the literature, but could not determine spray techniques that optimized intranasal spray efficacy ${ }^{(33)}$. As pointed out by Aggarwal et al., ${ }^{(38)}$ the reasons why topical nasal drug deposition patterns are hard to investigate include individual anatomical differences, different head positions, and the choice of administrative device (sprays or drops).

Table 3. Testing the null hypothesis that the presence or absence of inspiratory airflow does not improve efficacy of particle transport within the nasal cavity (Hypothesis \#2). The values were presented as means \pm standard deviation and were compared with the Student's t-test. P-value $<0.05$ indicate statistical significance (all cases).

\begin{tabular}{|c|c|c|c|c|}
\hline Head Position & Side & Flow $(n=5)$ & No flow $(n=5)$ & p-value \\
\hline \multirow[t]{2}{*}{ Upright } & Left (Affected) & $62.6 \pm 7.96$ & $15.2 \pm 2.05$ & 0.00010 \\
\hline & Right & $223.0 \pm 8.97$ & $72.0 \pm 6.44$ & $<0.00001$ \\
\hline \multirow[t]{2}{*}{ Head Back } & Left (Affected) & $62.2 \pm 7.79$ & $29.0 \pm 1.22$ & 0.00056 \\
\hline & Right & $220.0 \pm 10.51$ & $109.6 \pm 10.01$ & $<0.00001$ \\
\hline \multirow[t]{2}{*}{ Mygind's } & Left (Affected) & $61.6 \pm 7.77$ & $105.6 \pm 9.5$ & 0.00005 \\
\hline & Right & $219.2 \pm 10.03$ & $130.4 \pm 9.99$ & $<0.00001$ \\
\hline
\end{tabular}

Table 4. Testing the null hypothesis that head position does not impact spray particle deposition beyond the anterior region of the nose (Hypothesis \#3). The different head positions were compared using analysis of variance (ANOVA). P-value $<0.05$ indicate statistical significance (all cases).

$\begin{array}{ccc}\text { Airflow } & \text { Side } & \text { p-value } \\ \text { Present } & \text { Left (Affected) } & 0.97963 \\ & \text { Right } & 0.81635 \\ \text { Absent } & \text { Left (Affected) } & <0.00001 \\ & \text { Right } & <0.00001\end{array}$



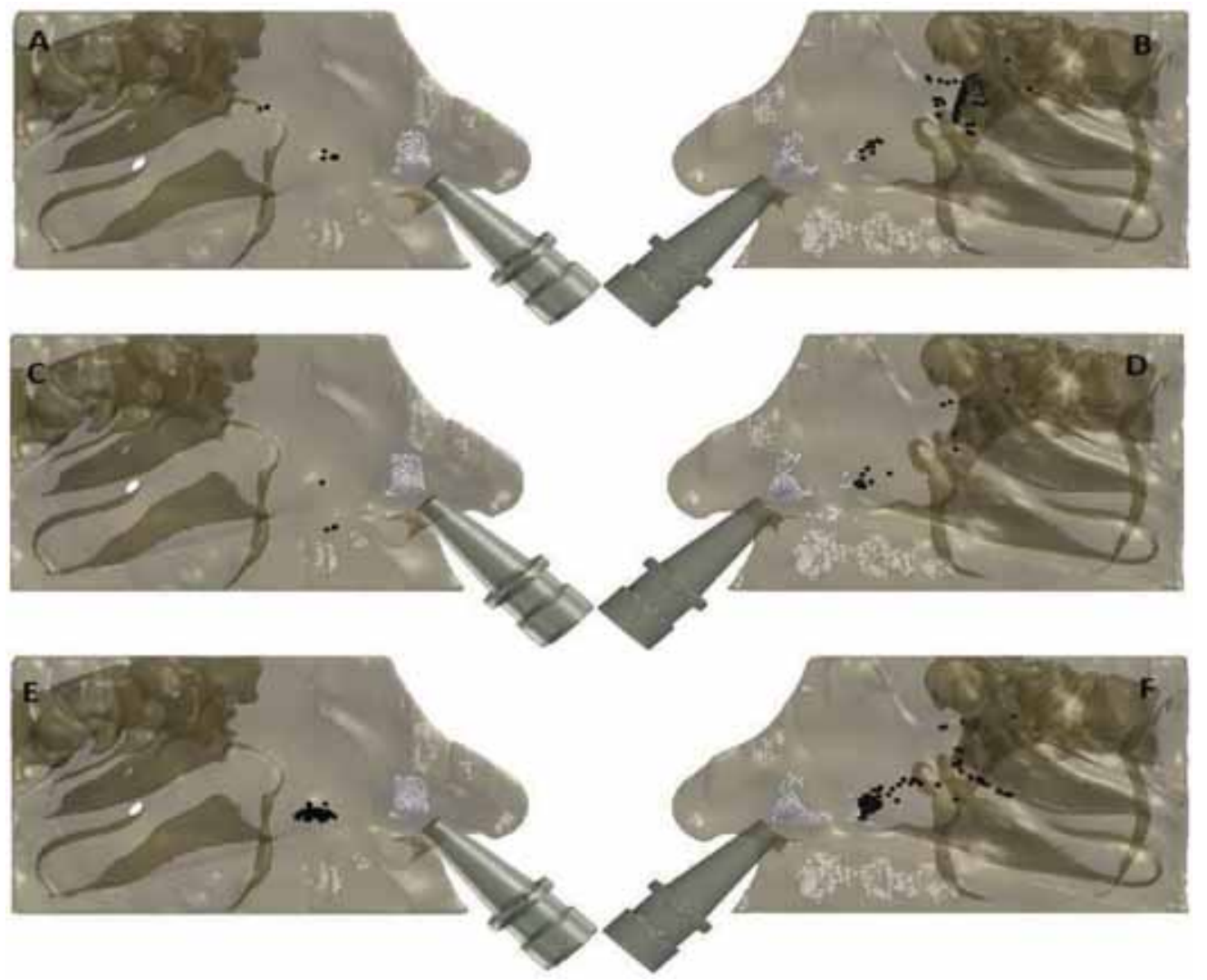

Figure 3. Simulated spray particle deposition pattern on the lateral wall. Particles colored in white deposited in the anterior region, while the black particles penetrated past the nasal valve area. (A) Left (Septal Deviation) side with inspiratory airflow present in the "head upright position". (B) Right side with inspiratory airflow present in the "head upright position". (C) Left (Septal Deviation) side with inspiratory airflow absent in the "head upright position". (D) Right side with inspiratory airflow absent in the "head upright position". (E) Left (Septal Deviation) side with inspiratory airflow absent in the Mygind's head position. (F) Right side with inspiratory airflow absent in the Mygind's head position.

The angle at which the simulated sprays were directed on each nasal side was guided by the recommendations of Benninger et al. ${ }^{(33)}$. However, these guidelines had to be interpreted in the context of the anatomy of the patient in this study such that the actual angle from the nostril center to the outer eye, which aimed the spray directly onto the lateral vestibule wall, was modified slightly to point toward the center of the eye rather than the outer corner. More significant modifications of this angle in other patients might be necessary to accommodate more severe or more anterior septal deviations. Further studies are needed to characterize the quantitative effects of such insertion angle modifications. In addition, our CFD simulations only accounted for regional particle deposition and did not determine the final destination of aerosols due to mucociliary transport or "runoff" effects of particles after deposition, two factors that may contribute to the taste that patients may perceive after sprayed medications are administered. Also, our simulation results were consistent with reports in the literature indicating that particle sizes ranging in aerodynamic diameter from 20-110 $\mu$ m were not easily respirable ${ }^{(3,4)}$.

Methods used to evaluate nasal deposition of topical medications include endoscopic visualization of dyed aerosols, CT imaging after application of contrast medium, or quantification of radioactivity or dye collected on strategically-placed surgical pledgets. CFD has several advantages over these other methods. First, patients are not exposed to any additional radiation other than that necessary for diagnostic CT scans. Second, quantitative, regional deposition patterns are obtained with much greater accuracy than is possible with other methods. Third, an unlimited number of simulations with varied parameters can be performed without any additional inconvenience or risk to the patient. A number of CFD studies of nasal spray deposition have been conducted ${ }^{(2,13,24-26,30-32,39)}$, indicating that these methods can be used to make reasonable predictions. By running multiple simulations in the same nasal cavity model, we demonstrate that the variations in deposition patterns between simulations were marginal. In addition, with the aid of a statistical power analysis, we determined an appropriate number of simulations to ensure 
that our study was adequately powered.

Previous studies investigating the influence of head position on effectiveness of topical nasal medications have produced mixed conclusions. Merkus and colleagues ${ }^{(7)}$ suggested that head position has a substantial influence on the deposition of topical nasal drugs into the middle meatus. In contrast, other studies found no significant effect of head positions on drug deposition efficiency ${ }^{(11,25)}$. As such, the impact of head positions on the efficacy of intranasal drugs has not been conclusively determined (33). Our CFD simulations indicate that particle transport and distribution were not sensitive to head position when inspiratory airflow was present but were highly sensitive to head position when inspiratory flow was absent. With no airflow present, the Mygind position afforded the best penetration, followed by head back and upright positions, respectively.

The significance of the present study cannot be overlooked given that the prevalence of septal deviation in healthy adults is between $19.5-26 \%{ }^{(14)}$. Allergic rhinitis and chronic rhinosinusitis, two conditions frequently treated with topical intranasal medications, are common conditions in the general population as well, making it likely that many patients have co-existing anatomic and allergric/inflammatory components contributing to nasal obstruction. In this population of patients, if a septal deviation or other anatomic deformity inhibits delivery of topical medication to the areas of the nasal cavity where it will have its greatest effect surgical correction of an underlying anatomic deformity may greatly increase the efficacy of medical management.

There are limitations of this preliminary study that warrant mentioning. First, while this study exposed and quantified the adverse effects of a moderate to severe septal deviation on INS sprays, our airflow simulations were limited to laminar, steady- state conditions, meaning that turbulence and the cyclic nature of airflow were not modeled. Second, the results reflect the nasal anatomy of a single subject with some evidence of nasal cycling, which this preliminary study did not account for. The extent to which mucosal edema resulting from the nasal cycle may play a role in the distribution of nasal medications is unclear. In conclusion, CFD simulations suggest that the impact of septal deviation on intranasal drug delivery was statistically significant. Effective topical drug delivery technique would ideally incorporate standardized patient instructions as to head position and appropriate inspiration and take into account the effect of anatomic deformities on drug deposition.

\section{Acknowledgments}

This research was funded by grants R01EB009557 and R01EB009557-01S1 from the United States National Institutes of Health (NIH)/National Institute of Biomedical Imaging and Bioengineering, under subcontract to the University of North Carolina from the Medical College of Wisconsin. This description of results from this research is solely the responsibility of the authors and does not necessarily represent the official views of the NIH. The authors thank Nicole Stelse, Kibwei McKinney, and Guiherme Garcia for their contributions to this work.

\section{Authorship contribution}

DOF, JSK and JSR: Design, acquisition of data, analysis and interpretation of data, drafting of the manuscript, final approval of draft. DC and SSP: Analysis and interpretation of data, revision of the manuscript, final approval of draft.

\section{Disclosure statement}

There is no conflicts of interest exist.

Sponsorships: None.

\section{References}

1. Illum L. Nasal drug delivery: new developments and strategies. Drug Discovery Today 2002; 7:1184-1189.

2. Kimbell JS, Segal RA, Asgharian Bet al Characterization of deposition from nasal spray devices using a computational fluid dynamics model of the human nasal passages. J Aerosol Med 2007; 20:59-74.

3. Frank DO, Kimbell JS, Pawar S, Rhee JS. Effects of Anatomy and Particle Size on Nasal Sprays and Nebulizers. Otolaryngol Head Neck Surg. 2011 Nov 2. [Epub ahead of print].

4. Suman JD, Laube BL, Dalby R. Comparison of nasal deposition and clearance of aeroso generated by nebulizer and an aqueous spray pump. Pharmaceutical Res. 1999; 16: 1648-1652

5. Djupesland PG, Skretting A. Nasal Deposition and Clearance in Man:
Comparison of a Bidirectional Powder Device and a Traditional Liquid Spray Pump. J Aerosol Med Pulm Drug Deliv. 2012. Jan 17. [Epub ahead of print].

6. Foo MY, Cheng Y-S, Su W-C, Donovan MD The influence of spray properties on intranasal deposition. J Aerosol Med 2007; 20: 495-508.

7. Merkus P, Ebbens FA, Muller B, Fokkens WJ. Influence of anatomy and head position on intranasal drug deposition. Eur Arch Otorhinolaryngol. 2006; 263: 827-832.

8. Blaiss MS, Benninger MS, Fronmer L, et al. Expanding choices in intranasal steroid therapy: Summary of a roundtable meeting. Allergy Asthma Proc. 2006; 27: 254-264.

9. Scheibe M, Bethge C, Witt M, Hummel T. Intranasal administration of drugs. Arch Otolaryngol Head Neck Surg. 2008; 134: 643-646.

10. Cheng YS, Holmes TD, Gao Jet al.
Characterization of nasal spray pumps and deposition pattern in a replica of the human nasal airway. J Aerosol Med. 2001; 14: 267-280.

11. Bateman ND, Whymark AD, Clifton NJ, Woolford TJ. A study of intranasal distribution of azelastine hydrochloride aqueous nasal spray with different spray techniques. Clin Otolaryngol. 2002; 27: 327-330.

12. Kesavan J, Bascom R, Laube B, Swift DL. The relationship between particle deposition in the anterior nasal passage and nasal passage characteristics. J Aerosol Med. 2000; 13: 17-23.

13. Schroeter JD, Kimbell JS, Asgharian B. Analysis of particle deposition in the turbinate and olfactory regions using a human nasal computational fluid dynamics model. J Aerosol Med. 2006; 19: 301-313.

14. Garcia GJ, Rhee JS, Senior BA, Kimbell JS Septal deviation and nasal resistance: an 
investigation using virtual surgery and computational fluid dynamics. Am J Rhinol Allergy. 2010; 24: e46-53.

15. Garcia GJ, Tewksbury EW, Wong BA, Kimbell JS. Interindividual variability in nasal filtration as a function of nasal cavity geometry. J Aerosol Med Pulm Drug Deliv. 2009; 22: 139-155.

16. Garcia GJM, Bailie N, Martins DA, Kimbell JS. Atrophic rhinitis: A CFD study of air conditioning in the nasal cavity. J Appl Physiol. 2007; 103: 1082-1092.

17. Garcia GJM, Mitchell G, Bailie N, Thornhill D, Watterson J, Kimbell JS. Visualization of nasal airflow patterns in a patient affected with atrophic rhinitis using particle image velocimetry. J Physics: Conference Series 2007; 85: 012032.

18. Garcia GJM, Rhee JS, Senior BA, Kimbell JS. Septal deviation and nasal resistance: An investigation using virtual surgery and computational fluid dynamics. Am J Rhinol Allerg 2009; 24: e46-53.

19. Garcia GJM, Schroeter JD, Segal RA, Stanek J, Foureman GL, Kimbell JS. Dosimetry of nasal uptake of water-soluble and reactive gases: A first study of interhuman variability. Inhal Toxicol. 2009; 21: 607-618.

20. Kimbell JS, Garcia GJ, Frank DO, Cannon DE, Pawar S, Rhee JS. Computed nasal resistance compared with patient-reported symptoms in surgically treated nasal airway passages: A Preliminary Report. Am J Rhinol Allergy. 2012; 26: 94-98.

21. Pawar SS, Garcia GJ, Kimbell JS, Rhee JS. Objective measures in aesthetic and functional nasal surgery: perspectives on nasal form and function. Facial Plast Surg. 2010; 26: 320-327.

22. Rhee JS, Pawar SS, Garcia GJ, Kimbell JS. Toward personalized nasal surgery using computational fluid dynamics. Arch Facial Plast Surg. 2011; 13: 305-310.

23. Schroeter JD, Garcia GJ, Kimbell JS. Effects of Surface Smoothness on Inertial Particle Deposition in Human Nasal Models. J Aerosol Sci. 2011; 42: 52-63.
24. Shanley KT, Zamankhan P, Ahmadi G, Hopke PK, Cheng YS. Numerical simulations investigating the regional and overall deposition efficiency of the human nasal cavity. Inhalation Toxicol. 2008; 20: 1093-1100.

25. Garlapati RR, Lee HP, Chong FH, Wang DY. Indicators for the correct usage of intranasal medications: A computational fluid dynamics study. Laryngoscope 2009; 119: 1975-1982.

26. Chen XB, Lee HP, Chong VF, Wang de Y. A computational fluid dynamics model for drug delivery in a nasal cavity with inferior turbinate hypertrophy. J Aerosol Med Pulm Drug Deliv. 2010; 23: 329-338.

27. Chen XB, Lee HP, Chong VF, Wang DY. Numerical simulation of the effects of inferior turbinate surgery on nasal airway heating capacity. Am J Rhinol Allergy. 2010; 24 e118-122.

28. Leong SC, Chen XB, Lee HP, Wang DY. A review of the implications of computational fluid dynamic studies on nasal airflow and physiology. Rhinology. 2010; 48: 139-145.

29. Wang SM, Inthavong K, Wen J, Tu JY, Xue CL. Comparison of micron- and nanoparticle deposition patterns in a realistic human nasal cavity. Respir Physiol Neurobiol. 2009; 166:142-151.

30. Inthavong K, Ge Q, Se CMK, Yang W, Tu JY. Simulation of sprayed particle deposition in a human nasal cavity including a nasal spray device. J Aerosol Sci. 2011; 42: 100-113.

31. Inthavong K, Tian ZF, Li HFet al. A numerical study of spray particle deposition in a human nasal cavity. Aerosol Sci Technol. 2006; 40: 1034-1045.

32. Inthavong K, Tian ZF, Tu JY, Yang W, Xue C. Optimising nasal spray parameters for efficient drug delivery using computational fluid dynamics. Comp Biol Med. 2008; 38 : 713-726.

33. Benninger MS, Hadley JA, Osguthorpe JDet al. Techniques of intranasal steroid use. Otolaryngol Head Neck Surg. 2004; 130: 5-24.

34. Rhee JS, Pawar SS, Garcia GJ, Kimbell JS.
Toward Personalized Nasal Surgery Using Computational Fluid Dynamics. Arch Facial Plast Surg. 2011; 13: 305-310.

35. Beals JA, Funk LM, Fountain R, Sedman R. Quantifying the distribution of inhalation exposure in human populations: distribution of minute volumes in adults and children. Environ Health Perspect. 1996; 104: 974-979.

36. Suman JD, Laube BL, Lin TC, Brouet G, Dalby $R$. Validity of in vitro tests on aqueous spray pumps as surrogates for nasal deposition. Pharmaceut Res. 2002; 19: 1-6.

37. Hallworth GW, Padfield JM. A comparison of the regional deposition in a model nose of a drug discharged from metered aerosol and metered-pump nasal delivery systems. J Allergy Clin Immunol. 1986; 77: 348-353.

38. Aggarwal R, Cardozo A, Homer JJ. The assessment of topical nasal drug distribution. Clin Otolaryngol Allied Sci. 2004; 29: 201-205.

39. Kleven M, Melaaen MC, Reimers M, Rotnes JS, Aurdal L, Djupesland PG. Using computational fluid dynamics (cfd) to improve the bi-directional nasal drug delivery concept. Food Bioproducts Processing 2005; 83: 107117.

Dennis O. Frank, Ph.D.

Department of Otolaryngology /

Head and Neck Surgery

University of North Carolina at

Chapel Hill

170 Manning Drive, CB \#7070

Chapel Hill

NC 27599, U.S.A

Tel: +1-919-843-6382

Fax: +1-919-966-7941

E-mail: dennis_frank@med.unc.edu 